\title{
Activity of Daily Living Performance amongst Danish Asylum Seekers: A cross-sectional study
}

\author{
Anne-Le Morville, OT, MSc****, Lena-Karin Erlandsson, PhD***, Mona Eklund, PhD***, \\ Bente Danneskiold-Samsøe, MD, DMSc*, Robin Christensen, PhD*, Kirstine Amris, \\ MD*
}

\begin{abstract}
Objective: The aim of this study was to evaluate the extent of Activities of Daily Living (ADL) ability impairment in newly arrived Danish asylum seekers. It was hypothesized that exposure to trauma and torture would negatively influence ADL performance and that measures of ADL ability would be lower in individuals exposed to torture as compared to the non-tortured.

Subjects: Forty-three newly arrived asylum seekers aged 20-50 years, from Iran, Afghanistan and Syria, were consecutively included in the study.
\end{abstract}

Method: ADL ability was assessed with the observation-based test Assessment of Motor and Process Skills (AMPS). Interviews were based on questionnaires about torture exposure, WHO-5 Wellbeing Index, Major Depression Inventory and Pain Detect Questionnaire. All participants were interviewed and tested using a linguistic interpreter.

Results: Thirty three (77\%) participants

\footnotetext{
^) The Parker Institute, Department of Rheumatology, Copenhagen University Hospital, Bispebjerg and Frederiksberg Hospitals, Denmark;

$\star \star)$ Metropolitan University College, Institute of Rehabilitation and Nutrition, Dept. of Occupational Therapy, Copenhagen, Denmark;

$\star \star \star)$ Department of Health Sciences, Lund University, Sweden
}

Correspondence to: almo@phmetropol.dk reported exposure to torture. The tortured did not differ significantly from the nontortured on measures of ADL ability (two-sample t-tests: Motor, $\mathrm{p}=0.36$; Process, $\mathrm{p}=0.82$ ). ADL performance impairment was observed in the overall study sample. Twelve had motor and 15 process ability measures below age norms and 2 below both AMPS motor and process cut-offs for effortless and efficient ADL performance. There were statistically significant - weak to moderate - correlations between self-reported psychological distress, VAS average pain, pain distribution and the AMPS measures. Conclusion: The study results supported significant ADL ability impairment in tortured as well as non-tortured newly arrived asylum seekers. Implementation of performance-based evaluation of ADL ability as part of the initial medical screening of this particular population should be considered.

Keywords: ADL ability, AMPS, torture survivors, pain

On top of the often traumatic circumstances, such as exposure to mass conflict and displacement, that has led to a person to flee the home country, those who seek asylum face a range of restrictions that are not experienced by the resident populations. In Denmark, asylum seekers, whether tortured or not, encounter constraints on access to 
work, education, private accommodation and do not have the same access to health care and social subsidies as the resident population. ${ }^{1}$ Until their pending case is decided and they receive refugee status, only acute medical needs are taken care of, but one can apply to the Danish Immigration Service for further medical attention. Many of the specialized rehabilitation centres do not offer rehabilitation before the asylum seeker has been granted asylum. The Danish Red Cross and other agents running the asylum centres offer counselling, but on a very limited basis. ${ }^{2}$ However, the right to rehabilitation should in principle be regarded as an obligation to rehabilitate torture survivors. ${ }^{3}$ The Convention against Torture states that rehabilitation 'refers to the restoration of function or the acquisition of new skills' in order to 'maximize possible self-sufficiency and function for the individual concerned' and 'aim to restore as far as possible, their independence, physical, mental, social and vocational ability; and full inclusion and participation in society'. ${ }^{4}$

Still, there has not been much research, if any, with explicit focus on Activities of Daily Living (ADL). An ADL task encompasses activities or tasks on a more complex problem-solving level, such as household chores, managing money and social participation in society. ${ }^{5}$ In a rehabilitation setting there is a need for systematically evaluating the quality of a person's ADL performance, measured at the level of activity and participation and not underlying body functions, personal factors, or environmental factors that may limit ADL performance. ${ }^{5,6}$

However, current evidence regarding ADL ability in torture survivors mainly derives from questionnaire-based self-reporting of ADL ability. ${ }^{7}$ There are no larger studies which have addressed ADL ability impairments encountered by traumatized asylum seekers or torture survivors based on standardized, observation-based assessment of ADL ability. Self-reports render an important subjective view on the perceived ADL problems, but supplementary assessment with objective assessments of ADL ability may provide a more thorough analysis of the ADL problems encountered. Thus, in order to plan for rehabilitation and intervention targeting daily activities, both the subjective self-report and an objective ADL ability measures should be present.

There are indications that exposure to torture, trauma and post-migration stress leads to a decrease in the number of daily activities and problems with $\mathrm{ADL}$ ability. ${ }^{7,8}$ In general, when suffering from illness or chronic health problems, the overall ADL ability is reduced. The number of daily activities might diminish and the quality of ADL ability declines over time, depending on the nature of the illness and the occurrence of hindering and facilitating factors in the surrounding environment. ${ }^{9-12}$

Previous studies from Denmark show that general health problems in newly arrived asylum seekers and refugees in Denmark are greater than in the background population, including high rates of psychological symptoms and pain problems. ${ }^{13,14}$ The long-term psychological sequelae are most often described in terms of major depression, generalized anxiety and post-traumatic stress. ${ }^{15}$ Persistent pain related to the musculoskeletal system and disabilities, often affecting $\mathrm{ADL}$, are reported to be the dominant physical complaints. ${ }^{7,16}$ At rehabilitation centres for torture survivors, chronic widespread pain (CWP) is often seen as one of the long-term physical complaints. ${ }^{16-18}$ Though most asylum seekers experience post-migration stress and have been subjected to traumatic incidents, research indicates that the asylum seekers who have been subjected 
to torture show increased health problems compared to asylum seekers who have not been subjected to torture. ${ }^{13,19}$

Due to these health problems such as psychological symptoms and pain problems encountered by asylum seekers in general and torture survivors in particular, it was hypothesized that exposure to trauma and torture would negatively influence ADL performance ability and that the obtained ADL scores would be lower in the group of asylum seekers who had been exposed to torture as compared to the non-tortured asylum seekers. Therefore the purpose of this paper is to describe the observed ADL ability of asylum seekers, and to uncover if there are any differences between tortured and non-tortured.

\section{Methods}

From the 1st of February until the 30th of June 2011, the first author recruited, interviewed and conducted the observationbased Assessment of Motor and Process Skills (AMPS) on newly arrived asylum seekers from Afghanistan, Syria and Iran, which represented the countries from which Denmark received the largest numbers of asylum seekers at the time. It was decided to include participants from said countries in order to keep the number of interpreters who needed introduction and instructions at a minimum and to advance positive collaboration between interpreters and the interviewer.

The interview and AMPS observation lasted for an average of two hours and took place in the centres' medical examination rooms and in the private rooms of the participants. Data from the Danish Red Cross files were used to gather information on the non-participants.

\section{Ethical considerations}

Asylum seekers are humans who are a disadvantaged and vulnerable population, due to their legal situation and exposure to traumatic incidents. They are also vulnerable as an economically and medically disadvantaged group as they do not have the same access to work and health care as the resident population. Asylum seekers may not dare say no to participation in a project, due to fear of influence on their asylum case and this poses a serious ethical problem. In order to prevent this, the following measures were taken.

The project team provided general information to the interested asylum seekers about the project and both written and thorough oral introduction and information was given to all, especially regarding voluntary participation, anonymity of identity, and confidentiality of the data. Written information about the project had been prepared in Dari, Arabic and Farsi, such that the asylum seekers should be able to read the information in their native language. If the asylum seeker was unable to read the written material or consent form in the native language, an interpreter was used.

The participants were informed that both the Danish Red Cross and the researchers are politically independent and that participation in the project would not and could not have any influence on their asylum case. Also, lack of participation or withdrawal from the project would not influence the asylum seeker's case. The interviews and observations had no curative purpose. If the asylum seeker displayed a need for medical treatment, the author would, after having received oral consent, contact Danish Red Cross health personnel in order to initiate appropriate diagnosis and treatment.

The local ethical committee approved the study in 2010 (KF 01-045/03). The project was also reported to the Danish Data Protection Agency. 


\section{Sampling and participants}

The participants were recruited through the Danish Red Cross, which is responsible for the registration of all newly arrived asylum seekers in Denmark, except for unaccompanied children under the age of 18 years. Quota refugees are not received in the asylum centres, and are therefore not part of this study. Exclusion criteria were living in the centre for more than four weeks, a diagnosis of severe mental or physical illness, severe handicaps and pregnancy in the last trimester, as the latter though a natural condition might influence the ADL performance. The participants were invited to participate in the project during their initial medical screening and were then referred to the researchers if interested.

Final inclusion in the study was based on written informed consent. By these procedures participants were consecutively recruited.

The routinely used Red Cross' telephone interpreters were used during the interviews and observation-based assessment of ADL ability. Interpreters were on stand-by even if the asylum seeker and the interviewer were able to communicate in the same language, in order to ensure that the language barriers were minimized. The use of a telephone interpreter has the advantage that the presence of a third person does not disturb the interview or performance of the AMPS test.

\section{Instruments}

Observation based assessment:

Assessment of Motor and Process Skills:

The ADL test; Assessment of Motor and Process Skills (AMPS) ${ }^{5}$ is an observationbased evaluation of the quality of ADL ability, developed to establish the extent of an individual's ability to perform and complete ADL tasks independently and in a safe and efficient manner, also called ADL performance. The performance skills in ADL e.g. reaches for, grips and lift a coffee cup, are the smallest units of observable actions that are linked together, one after another, in the process of executing a daily life task..$^{5,20}$ The AMPS has been developed in order to provide an activity-focused documentation and facilitate activity- based intervention/ rehabilitation, and does not assess the underlying functional problems. The AMPS has been standardized and validated on more than 100,000 individuals including healthy subjects globally and cross-culturally, and several studies support good test-retest and rater reliability as well as validity across diagnostic groups. The AMPS is administered by trained and calibrated occupational therapists. Further, the AMPS measurement model incorporates the use of Rasch analysis, and therefore provides equal-interval linear measures of the quality of ADL task performances. Two separate measures are reported, one for ADL motor ability (moving self and objects) and one for ADL process ability (organizing and adapting actions). ${ }^{5}$

Before the observation test, the persons were interviewed about daily activities, to ensure that the chosen tasks are well known and relevant to the person. During administration of the AMPS the person performs at least two of 111 standardized PADL (self-care ADL) and IADL (domestic ADL) tasks. The chosen tasks should be of appropriate challenge to the person and at the same time meaningful and relevant to that person's daily life. ${ }^{5}$

Following the observation, $16 \mathrm{ADL}$ motor and $20 \mathrm{ADL}$ process skill items are used to rate the quality of the performance of each of the chosen ADL tasks according to the ease, efficiency, safety and independence observed. A four-point ordinal scale is used $(1=$ markedly deficient, 2 = ineffective, $3=$ questionable, $4=$ competent). Calibrated 
AMPS raters use computer-scoring software to convert the person's raw scores into two overall linear ADL ability measures, one for ADL motor ability and one for ADL process ability. These two overall ADL measures are adjusted for ADL task difficulty and rater severity (i.e. how strict the rater scores the observed performance) and are expressed in logistically transformed probability units (logits). The results of the AMPS test includes the expected range of ADL measures for healthy, age-matched peers, based on more than 12,000 individuals, and indicates whether the person tested has ADL motor and/or ADL process scores that are within that expected range of ADL ability. The expected range is delineated by $\pm 2 \mathrm{SD}$ from the age-matched mean for a healthy sample; $95 \%$ of healthy people are expected to have ADL ability measures within this range.

As seen in Table 1 , ability measures above the 2.00 logits cut-off on the ADL motor scale and above the 1.00 logit cut-off on the ADL process scale indicate effortless, efficient, safe and independent ADL task performance in everyday life, whereas scores below those cut-offs indicate increased effort or fatigue during task performance. ${ }^{5}$
The AMPS has mainly been applied in studies of ADL ability in psychiatric, neurologic, geriatric and healthy populations, but has also been introduced in studies of rheumatologic patients including patients with CWP $(5,21)$. The AMPS has also been shown to be a sensitive outcome measure in intervention studies concerning rehabilitation. $^{5}$

ALM, who is a trained AMPS observer, interviewed and conducted the AMPS observations.

\section{Questionnaires and Participant- Reported Outcomes}

The baseline interview included a questionnaire used to retrieve the following basic information: age, gender, country of origin, civil status and education.

In this study, the Declaration of Tokyo, adopted by the congress of the World Medical Assembly (WMA) in 1975 was used as the definition of torture. ${ }^{22}$ The participants were asked about whether they had been imprisoned or arrested, and whether they had been exposed to torture based on a simple yes/no question. In order to identify primary torture survivors, the torture history

Table 1: Competence cut-offs for ADL ability as measured by AMPS

\begin{tabular}{lll} 
Level of ADL ability & Motor ability & Process ability \\
\hline $\begin{array}{l}\text { Effortless, efficient, safe and independent task } \\
\text { performance }\end{array}$ & $>2.0$ logits & $>1.0$ logits \\
\hline $\begin{array}{l}\text { Increased effort or fatigue during task performance } \\
\text { indicating need for assistance regarding shopping, } \\
\text { heavy housework and home maintenance tasks }\end{array}$ & $<1.5$ logits & $<1.0$ logits \\
\hline $\begin{array}{l}\text { Need for moderate to maximal assistance regarding } \\
\text { meal preparation, self-care, shopping, heavy } \\
\text { housework and home maintenance tasks }\end{array}$ & $<1.0$ logits & $<0.70$ logits \\
\hline
\end{tabular}

* A change of more than 0.3 logits is considered clinically significant 
was further elaborated based on a torture item checklist incorporating the most frequently used physical and psychological torture methods directed against the individual.

The checklist consisted of eight physical items (1: un-systematic beatings, 2 : suspension, 3: falanga, 4 : forced positions, 5: rape or other sexual assault, 6: strangulation, 7: electricity/burns; and 8: other methods) and eight psychological items (1: deprivation of basic needs, 2: isolation, 3: sensory deprivation or over-stimulation, 4: degrading treatment, 5: witnessing torture of others, 6 : witnessing sexual assaults on others, 7 : mock executions; and 8: other methods).

The following standardized questionnaires were applied to all participants:

WHO-5 Well-being Index: WHO-5 is a 5-item questionnaire used to calculate the risk for stress and depression. ${ }^{23}$ The questions are rated on a 6-point Likert scale from 0 (=not present) to 5 (= constantly present). The theoretical raw score ranges from 0 to 25 and is transformed into scales from 0 (worst thinkable well-being) to 100 (best thinkable well-being). A raw score below 13 indicates poor well-being.

\section{The Major Depression Inventory} (MDI): MDI is a validated 10 -item selfreport instrument for depression that can be scored both according to the DSM-IV and the ICD-10 algorithms for depressive symptomatology and according to severity scales by the simple total sum of the items, the total score ranging from $0-50 .{ }^{24} \mathrm{~A}$ MDI sum score above 30 indicates major depression, between 26 and 30 moderate depression, between 21 and 25 mild depression, and below 21 no depression. In this study the ICD-10 algorithm for depression was used.

Self-Rated Health (SRH): The first item of the Medical Outcomes Scale (MOS) 36-item, short-form health survey (SF-36) $)^{25}$ was used as an overall self-estimate of health. It is considered a reliable and valid one-item estimate of self-rated health. ${ }^{26}$ The person rates his or her health on a five-point scale from $1=$ excellent to $5=$ poor.

\section{Pain Detect Questionnaire (PDQ):} The PDQ is a screening questionnaire developed and validated to predict the likelihood of a neuropathic pain component being present in individual patients. ${ }^{27} \mathrm{It}$ comprises questions regarding pain intensity (VAS intensity values for current, average, and worst pain), course of pain (selection between four pain course patterns), subjective experience of a radiating quality of the pain (yes/no), and the presence and perceived severity of seven somatosensory symptoms of neuropathic pain rated on a $0-5$ verbal rating scale (never, hardly noticed, slight, moderate, strong, and very strong). For diagnostic purposes, a validated algorithm is used to calculate a total score ranging from 0 to 38 based on the respondent's answers. A total score above 18 indicates that a predominantly neuropathic pain component is likely, whereas a total score below 12 indicates that this is unlikely.

Further, a question about duration of pain was included $(1=0-3$ months; $2=4-6$ months; $3=7-12$ months; $4=12+$ months).

\section{Statistical analysis}

All analyses were done applying SAS software (v. 9.2 Service Pack 4; SAS Institute Inc., Cary, NC, USA). All descriptive statistics and tests are reported in accordance to the recommendations of the 'Enhancing the QUAlity and Transparency Of health Research' (EQUATOR) network: the STROBE statement' ${ }^{28}$ In order to evaluate the empirical distributions of the continuous outcomes, visual inspection was used to suggest whether the assumption of normality 
was reasonable. The PROC UNIVARIATE statement was used for summarizing the data. Analyses were conducted as described in the protocol, on the 'available cases' population (i.e., no imputation for missing data). Two sided statistical significance tests were used; P-values $<.05$ were considered statistically significant.

Continuous outcome data, assumed sampled from a normal distribution, were analysed using two-sample t-test for means, using the Satterthwaite approximation assuming unequal variances by default. The PROC TTEST was used for these with corresponding mean differences and 95\% CIs. If the assumption of normality was not reasonable, we analysed the data with the nonparametric 'Wilcoxon Rank Sum' test using PROC NPAR1WAY; in this case the 'mean difference' was replaced with the calculated 'median difference'; the 95\% confidence limits were estimated from an approximated standard error, based on the 'Wilcoxon P-value' from a Wald-Z-test. In order to evaluate the potential bivariate associations between the different variables the Spearman Rank Order was used to test whether there was a statistically significant correlation.

\section{Power and sample size considerations}

Studies have shown that the ADL process measure is a better indicator than the AMPS motor measure of need for assistance when living in the community. ${ }^{5}$ Based on this, the process measure from the AMPS was chosen as the main outcome measure.

Based on a Danish study indicating high rates, ${ }^{13} 40-45 \%$, of torture, as defined by WMA, ${ }^{22}$ in a Danish asylum seeker population, we anticipated an equal distribution of individuals who had been exposed to torture and individuals who had not. For a twosample t-test with a two-sided significance level of $p=0.05$, a sample size of 19 per group would be required to obtain a power of at least $85 \%$ to detect a difference in the AMPS process measure between the means 2.0 and 1.5 logit.

\section{Results}

\section{Participants}

In all, 176 asylum-seekers, fitting the inclusion criteria, from the selected nations were referred to the Red Cross Centre during the study period. Eighty-nine of these declined to partake, leaving 87 eligible for inclusion. Out of these, 67 gave informed consent after a more thorough introduction, but as illustrated in Figure 1, 20 study participants dropped out of the study for various reasons, such as being moved to another centre or not showing up at appointed times. Moreover, for four of the participants the interview and AMPS test had to be terminated prematurely due to emotional reactions. This resulted in a total study sample of 43 participants that were interviewed and completed the AMPS-test (i.e. available case scenario).

\section{Demographic data}

Demographic data are presented in Table 2. The participants came from Syria $(n=8$; $19 \%)$, Iran ( $n=18 ; 42 \%)$ and Afghanistan $(n=17 ; 39 \%)$. Their mean age was 30 years (range 20-50), the mean level of education was 10 years (range $0-19)$ and $24(56 \%)$ of the asylum seekers had arrived to Denmark unaccompanied by family members or spouses. There were no differences between the study sample of 43 participants and the 133 non-participants regarding marriage $(p=0.092)$, age $(p=0.393)$, gender $(p=0.160)$ or education $(p=0.687)$. There was a significantly higher $(\mathrm{p}=0.011)$ prevalence of torture in the participants group (77\%), than amongst the non-participants (54\%). 
Figure 1: Flowchart of inclusion of participants.

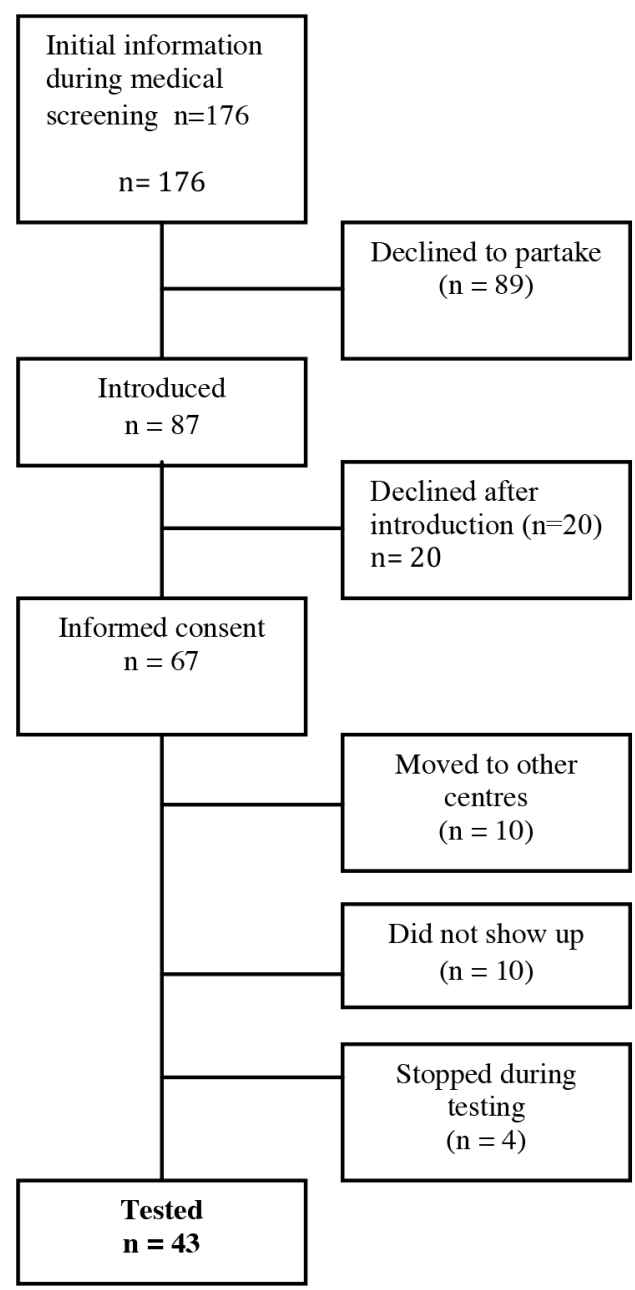

Table 2: Demographics

\begin{tabular}{l|ll}
\hline & Total $\mathbf{n}=43$ & \\
\hline & Male=36 & Female=7 \\
$\begin{array}{l}\text { Age } \\
\text { (years) }\end{array}$ & $30 \pm 7.45$ & $32 \pm 9.10$ \\
Married, yes & 21 & $(24-50)$ \\
$\begin{array}{l}\text { Education } \\
\text { (years) }\end{array}$ & $10 \pm 5.64$ & 6 \\
& $(0-19)$ & $(6-16)$
\end{tabular}

\section{Prevalence of torture and applied torture methods}

Thirty-three (77\%) participants reported exposure to torture. Six from Syria, 14 from Iran and 13 from Afghanistan reported exposure to torture either in their homeland or during the flight to Denmark. All the participants had experienced traumatic incidents such as armed conflict and threats to themselves or their family. The most commonly applied physical torture methods were unsystematic beatings or blows, suspension by the extremities and forced positions. Frequent psychological torture methods were isolation, deprivation of basic needs and witnessing torture of others.

\section{Observation-based assessment of ADL ability and differences between groups}

Figure 2 presents the distribution of the AMPS measurements, while also showing competence cut-offs for effortless and efficient ADL performance on ADL motor and ADL process measures for the investigated sample and the AMPS reference group of healthy individuals of comparable age. ${ }^{8}$ The figure shows that ADL motor skills impairment is less diverse, whereas process skills measures are more diverse. None of the participants had both ADL motor and ADL process ability measures above the expected age mean. All $43(100 \%)$ participants had ADL motor ability measures and 35 (81\%) ADL process ability measures below the mean of those found in healthy groups of the same age. Twelve (28\%), 10 of who had been subjected to torture, were below the expected ADL motor ability range and fifteen, of whom 11 had been subjected to torture, were below the expected range of ADL process ability. Fifteen (35\%) were below the 2.00 logits ADL motor competence cut-off indicating increased effort during ADL-task performance. Eleven (26\%) of the partici- 
pants were below the 1.00 logit ADL process competence cut-off indicating inefficiency during task performance as well as a potential need of assistance for community living. Further, two participants, both subjected to torture, were below both the 1.50 logits ADL motor cut-off and the 1.00 logit ADL process cut-off indicating a definite need of assistance in community living and self-care. The most used observation tasks were within the domestic tasks, such as preparing coffee and biscuits and serving at a table, cleaning the room/ bathroom and doing the dishes.

As shown in Table 3, there was no significant group difference present in the mean ADL motor or process ability measures.

\section{Self-reported health variables and differences between groups}

Of the 43 participants, 36 (84\%) scored below 50 on the WHO-5 indicating that the sample as a whole suffered from stress and low well-being. This was also found with the MDI, using the ICD-10 algorithm for depression, where, 16 (37\%) showed signs of severe depression, seven (16\%) showed signs of moderate depression and five $(12 \%)$ had signs of distress and milder depression. 13 participants $(35 \%)$ rated their health as

Figure 2: Distribution of groups on AMPS motor and process scales

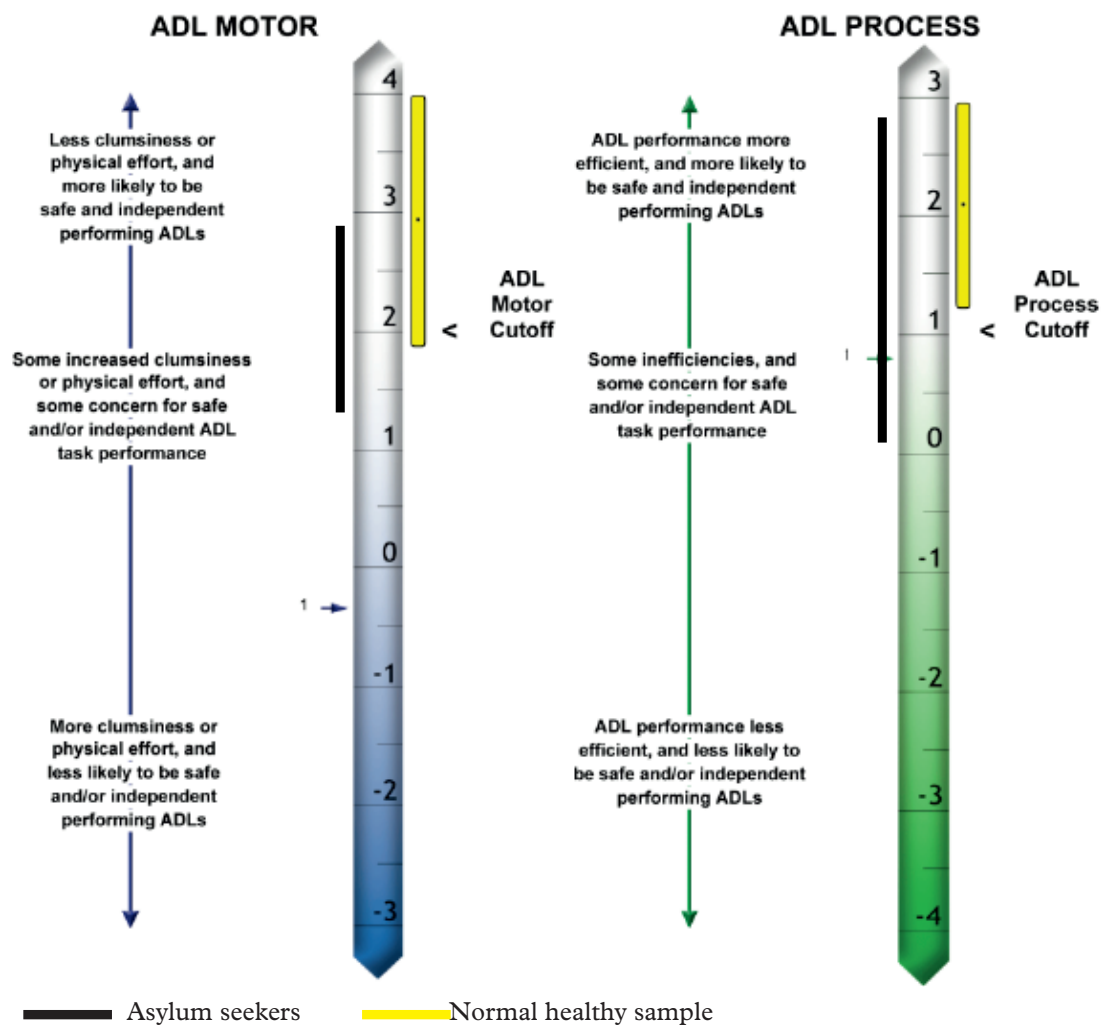


Table 3: Differences between non-tortured and tortured

\begin{tabular}{|c|c|c|c|c|}
\hline & Mean \pm SD & Mean \pm SD & $\begin{array}{l}\text { Difference } \\
(95 \% \mathrm{CI})\end{array}$ & p-value \\
\hline$N=43$ & No torture & Torture & & \\
\hline Variables & $\mathrm{N}=10$ & $\mathrm{~N}=33$ & & \\
\hline Age $(\text { years })^{\star}$ & $29 \pm 8.56$ & $30 \pm 7.51$ & $-1.23(-7-.71$ to 5.24$)$ & 0.69 \\
\hline AMPS motor ${ }^{\star}$ & $2.24 \pm 0.33$ & $2.12 \pm 0.42$ & $0.12(-0.15$ to 0.39$)$ & 0.36 \\
\hline AMPS process ${ }^{\star}$ & $1.35 \pm 0.62$ & $1.41 \pm 0.64$ & $-0.05(-0.53$ to 0.43$)$ & 0.82 \\
\hline $\begin{array}{l}\text { WHO-5^ } \\
\text { (Score 0-100) }\end{array}$ & $35 \pm 15.17$ & $29 \pm 22.13$ & 5. $28(-7.03$ to 18.52$)$ & 0.37 \\
\hline $\begin{array}{l}\text { MDI* } \\
\text { (Score 0-50) }\end{array}$ & $26.2 \pm 9.27$ & $31.48 \pm 11.80$ & $-5.28(-12.78$ to 2.22$)$ & 0.16 \\
\hline Self-rated health ${ }^{\star \star}$ & 2.0 (IQR: 1-2) & 2.0 (IQR: $1-3$ ) & n.a. & 0.36 \\
\hline $\begin{array}{l}\text { Region distribution }{ }^{\star \star} \\
(0-4+)\end{array}$ & 1 (IQR: 0-1) & 1 (IQR: 0-3) & 0 & 0.48 \\
\hline $\mathbf{P D Q} \star \star \star$ & 4.5 (IQR: 0-14) & $7.0(0-13)$ & $-2.5(-8.3$ to 3.3$)$ & 0.85 \\
\hline VAS current ${ }^{\star \star}$ & 0.0 (IQR: 0-3) & 0.0 (IQR: 0-5) & n.a. & 0.37 \\
\hline VAS worst ${ }^{\star \star}$ & 6.5 (IQR: 5-8) & 8.0 (IQR: 0-10) & $-1.5(-8.2$ to 5.2$)$ & 0.66 \\
\hline VAS average ${ }^{\star \star}$ & 4.5 (IQR: 2-6) & 4.0 (IQR: 0-6) & $0.5(-2.2$ to 3.2$)$ & 0.71 \\
\hline Time w. pain ${ }^{\star \star}$ & 4 (IQR: 3-4) & 4 (IQR: 0-4) & n.a. & 0.62 \\
\hline
\end{tabular}

${ }^{\star}$ Two-tailed t-test ${ }^{\star}$ assuming unequal variances

$\star \star$ Median [Interquartile range]; analyzed based on Wilcoxon (rank sums) scores

Table 4: Correlations between AMPS motor measure and AMPS process measures and self-reported variables

\begin{tabular}{|c|c|c|c|c|}
\hline $\begin{array}{l}\text { Variable } \\
\text { N } 43\end{array}$ & $\begin{array}{l}\text { AMPS Motor } \\
\text { Spearman's rho }\end{array}$ & P-value & $\begin{array}{l}\text { AMPS Process } \\
\text { Spearman's rho }\end{array}$ & P-value \\
\hline $\begin{array}{l}\text { Physical torture metods } \\
(1-8)\end{array}$ & -0.143 & 0.360 & 0.134 & 0.393 \\
\hline $\begin{array}{l}\text { Psychological torture } \\
\text { methods (1-8) }\end{array}$ & -0.063 & 0.686 & 0.290 & 0.060 \\
\hline Sum of torture methods & -0.106 & 0.498 & 0.242 & 0.118 \\
\hline $\begin{array}{l}\text { WHO-5 } \\
\text { Score }(0-100)\end{array}$ & 0.434 & $0.004^{\star}$ & 0.459 & $0.002^{\star}$ \\
\hline $\begin{array}{l}\text { MDI } \\
(0-50)\end{array}$ & -0.325 & $0.033^{\star}$ & -0.341 & $0.025^{\star}$ \\
\hline $\begin{array}{l}\text { PDQ score } \\
(0-38)\end{array}$ & -0.201 & 0.196 & 0.036 & 0.820 \\
\hline $\begin{array}{l}\text { VAS current pain } \\
(0-10 \mathrm{~cm})\end{array}$ & -0.156 & 0.317 & 0.070 & 0.655 \\
\hline $\begin{array}{l}\text { VAS average pain } \\
(0-10 \mathrm{~cm})\end{array}$ & -0.302 & $0.049^{\star}$ & -0.189 & 0.224 \\
\hline $\begin{array}{l}\text { VAS worst pain } \\
(0-10 \mathrm{~cm})\end{array}$ & -0.238 & 0.124 & -0.110 & 0.483 \\
\hline $\begin{array}{l}\text { Pain location } \\
(0-=>4 \text { regions })\end{array}$ & -0.420 & $0.005^{\star}$ & -0.147 & 0.348 \\
\hline $\begin{array}{l}\text { Self-rated health } \\
(1-5)\end{array}$ & -0.042 & 0.787 & -0.159 & 0.309 \\
\hline
\end{tabular}


excellent or very good and $15(35 \%)$ rated their health as fair or poor. As seen in Table 3 no significant differences between the tortured and non-tortured group were observed in self-rated health, WHO-5 well-being or MDI depression scores. Regarding pain, 12 (28\%) participants reported that they had no pain at all, 13 $(30 \%)$ reported pain in one body region, and five $(12 \%)$ in two body regions. Widespread pain, defined as pain in three or more body regions, was reported by $13(30 \%)$ and duration of the pain problem of more than 6 months was reported by 28 (65\%). The most prevalent pain complaints were headaches and stomach aches. Musculoskeletal pain in the lower extremities was reported by 12 (28\%), in the upper extremities by $10(23 \%)$, in the lower back by nine $(21 \%)$, in the neck region by seven (16\%) and in the feet by five $(12 \%)$. Based on the cut-off algorithm of the PDQ a predominantly neuropathic pain component was likely in four $(9 \%)$ of the participants, three of which were tortured and one not tortured. A neuropathic pain component could not be refuted in eight $(19 \%)$, and was unlikely in the remaining 31 (72\%).

As seen in Table 3, no statistically significant between-group difference was present in any of the self-reported measures of pain.

\section{ADL motor and process ability measures and correlations with self-reported health variables}

Associations as seen in Table 4, between variables for the sample as a whole between self-reported psychological health and ADL motor and ADL process ability measures according to the AMPS are presented in Table 3. As anticipated, the analyses revealed significant correlations $(\mathrm{P}<.05)$ between self-reported psychological distress measured with the WHO-5 and MDI and observed ADL motor measure (WHO-5: $\mathrm{r}=0.434$; MDI: $\mathrm{r}=$ -0.325) and ADL process ability measure (WHO-5: $r=0.459$; MDI: $r=-0.341$ ).

Furthermore, a significant correlation between observed ADL motor ability measure and the average VAS pain score ( $\mathrm{r}$ $=0.30)$ and pain location $(r=0.42)$ was found.

\section{Discussion}

The results of the study supported our hypothesis of substantially impaired ADL ability in newly arrived asylum seekers. Significantly lower mean ADL motor and process ability scores were obtained in our study population, compared to the ADL motor and process ability scores found in the AMPS reference group of healthy adults (5). The findings indicated increased effort, fatigability and inefficiency during ADL-task performance. Unexpectedly, the study results did not support the hypothesis of a further detrimental effect of exposure to torture. No statistically significant group differences, tortured vs. non-tortured, in the mean ADL motor or process ability measures were observed. This lack of between-group differences was surprising, but may be explained by the fact that other traumas than torture directed against the individual itself, including secondary victimisation, and the stress and strain of fleeing and often living under poor conditions that most asylum seekers experience may in itself have a negative impact on ADL ability. The lack of between-group differences might also be due to the high prevalence of torture survivors and/or the small sample, as the power calculations showed that 19 in each group was needed.

The high prevalence of torture in this sample was not foreseen, as a 50/50 ratio was expected based on earlier studies, which may 
also have influenced the study results. ${ }^{13}$ It is difficult to obtain precise figures for the number of torture survivors among traumatized asylum seekers and refugees. The assessment of torture is, across the majority of surveys, reliant on self-report, however, leaving open the possibility of personal and culturally determined understandings of the term. ${ }^{29}$ Also, the applied definition of torture may vary across studies and influence reported prevalences. According to Steel et al.s review from $2009,{ }^{30} 21 \%$ of populations exposed to mass conflict and displacement were exposed to torture, but they do not note which definition of torture they have used. ${ }^{30}$ However, Masmas et al., ${ }^{13}$ who used the WMA definition of torture, ${ }^{22}$ found that the prevalence of torture in Danish asylum seekers from nations such as Iran, Afghanistan and Syria tended to be higher (55\%) than in other nationalities. The selection of nationalities may therefore have influenced the frequency of exposure to torture in our study sample. The observed significant difference in the reporting of exposure to torture between participants and non-participants, however, may be explained by the method of questioning, as the non-participants only answered a yes/no question, whereas the participants were asked questions about exposure to specific methods of torture. The reported torture methods were similar to those reported by other studies, ${ }^{13}$ though the use of falanga (beating of the soles) has been reported more frequently in previous research. ${ }^{31}$

Evaluated with the AMPS, and compared to competence cut-offs in the healthy AMPS reference group, the majority of the asylum seekers included in our study demonstrated measures of low ADL motor and/or ADL process skills, essential for the performance of activities of daily living. ${ }^{5}$ Further emphasizing the extent of performance impairment encountered by the study sample, two of the participants, both subjected to torture, had ADL ability measures below the "level of assistance" cut-offs on both AMPS scales, indicating a need of assistance with ADL tasks such as shopping, heavy housework, home maintenance tasks and self-care. Whereas both the ADL motor and ADL process measure can reflect independence in $\mathrm{ADL}$ performance, the ADL process measure has been shown to be a better indicator of need for assistance when living in the community. ${ }^{5}$ The ability to adapt to and overcome physical impairments is related to the planning and executing of a given task, i.e. ADL process skills. The sample showed ADL process skills impairment ( $35 \%$ below expected age cut-off), which is notable as it may limit the individual in adapting and overcoming the physical impairments and/or experience of pain. The study sample also fell below the age-matched mean on ADL motor measure $(27 \%$ below expected age cut-off), indicating increased effort and fatigability during task performance. Persons who use increased effort and experience fatigue during daily activities are more likely to decrease their social participation and participation in society in general. ${ }^{32}$ The observed low ADL ability measures, indicating increased effort, fatigability, inefficiency and a potential need of assistance at the level of doing light housework and shopping, should therefore be taken into consideration. In order to prevent isolation and further deterioration in ADL ability and support daily activities and social participation, a focus on ADL ability seems needed, when planning for example accommodation in both centres and individual apartments outside centres.

Based on limits proposed by Cohen, ${ }^{33}$ low to moderate correlations were observed between self-reported measures of psycho- 
logical well-being and AMPS measures of ADL motor and process ability skills, as well as between pain distribution and VAS average pain and AMPS measures of ADL motor skills. Since the observed association between psychological distress and ADL process skills was only low to moderate, other factors need to be taken into consideration. It is possible that impaired process ability reflects cognitive deficits important for efficient task performance rather than psychological distress. Our evaluation did not include an assessment of cognitive dysfunction, however, known to be a prominent feature of posttraumatic stress as well as chronic pain. ${ }^{34}$ The impact of cognitive dysfunction on ADL ability as measured by the AMPS should thus be tested in future studies.

High ratings of psychological distress as well as low ratings of well-being and general health were observed in our study population, all of which may influence ADL ability. However, no group differences (tortured vs. non-tortured) were present in scores on MDI or WHO-5 as opposed to prior research. ${ }^{13}$ Several factors may contribute to the development of psychological distress aside from exposure to torture. These symptoms may be caused by subjection to the experience of armed conflict, civil unrest, separation from and uncertainty about the family and the flight itself. Given a relatively small sample size and a preponderance of torture survivors in the overall study sample the current study may also have been underpowered to show such a group difference.

Pain is an important factor when discussing ADL ability, as it is well-documented that persistent pain interferes with the ability to perform ADL and social participation. ${ }^{21,32}$ In our study sample, the prevalence of pain was high. Thirty-one (72
$\%)$ of the participants reported that they suffered from a pain problem (23 in the tortured and eight in the non-tortured group), though not necessarily constant pain and pain at the time of examination as reflected by a low mean score on VAS current pain in the overall study population. In $28(65 \%)$ of the participants, the pain problem was reported to be of more than six months duration, indicating the possibility of persistent pain. However, no statistically significant in-between group differences (tortured vs. non-tortured) were observed and numerous determinants may combine to complicate the understanding of pain in asylum seekers. It is possible that the study was underpowered to detect such group difference or that pain may pertain to causes other than the torture trauma itself. Posttraumatic stress and posttraumatic stress symptoms have been found to be strongly associated with the report of pain and pain-related disability. ${ }^{35}$ In accordance with other studies of asylum seekers, pain in the musculoskeletal system, headache and stomach ache were predominant ${ }^{13,16}$ and widespread pain, defined as pain in three or more body regions, were reported by $30 \%$.

There is substantial documentation that persistent pain, mostly described by pain location, is a prevailing long-term consequence of torture. ${ }^{7,13,19}$ Studies of torture survivors mainly conducted in specialized tertiary care settings, however, are beginning to establish connections between some forms of torture and persistent pain and other symptoms, better described by pain mechanism than by site of pain. Nerve lesions caused by blows, strangulation, traction and other forces are probably common in survivors of torture and neuropathic pain conditions have been linked with the use of specific torture methods. ${ }^{18,36,37}$ Even so, a predominantly neuropathic pain component 
was only likely in four (9\%) of the participants based on the cut-off algorithm of the Pain Detect. Several chronic muscular pain syndromes that have been described and often diagnosed in other clinical settings such as chronic widespread pain (CWP) or fibromyalgia, share common characteristics not unlike the constellation of symptoms found in our study sample; regional or generalized musculoskeletal pain, associated with psychological distress, fatigue, headache and visceral symptoms. Further, substantial ADL ability impairments, dominated by ADL motor skill deficits, have been reported in patients with CWP evaluated with the AMPS. ${ }^{21} \mathrm{~A}$ low to moderate correlation between the AMPS motor ability measure and pain distribution $(r=0.42)$ was also observed in this study. It could therefore be speculated that aberrant central pain processing and motor skill deficiency due to central nervous system involvement play a pathogenic role in subsets of our study sample.

\section{Limitations of the study}

Based on a power calculation with AMPS process measures as "primary outcome" we aimed at inclusion of 50 participants. Due to the dropout and a high prevalence of torture exposure in the referral population, we ended up having a somewhat different sample than intended with a preponderance of torture survivors. This points to the need for including more asylum seekers in future studies, though the participants made up $24 \%$ of the available asylum seekers from the chosen countries at the time. This relatively high rate of participants could be a sign of hope of secondary gain, though measures were taken to prevent this.

The study was sufficiently powered to detect a tentative group difference in AMPS measures, but may have been underpowered to assess group differences in self-reported measures of pain, health and psychological well-being. The AMPS is inter-culturally validated, ${ }^{8}$ but this is the first study to apply the AMPS on a population of traumatized asylum seekers from the Middle East, and with the use of an interpreter. Regarding norm development in relation to a population of asylum seekers from the Middle East, the AMPS has been tested across many cultures, and the norms used in the AMPS should be considered applicable. That a trained and calibrated AMPS observer performed the AMPS tests, has also strengthened the results, but they could be questioned due to the use of an interpreter. The AMPS proved to be easy to administrate, and the tasks were well-known and relevant to the participant's daily life. Using the AMPS provides a measure for the observed quality of the ADL ability as opposed to the self-rated ADL ability, which might be influenced by psycho-social factors, making the AMPS a valid measure for ADL ability.

The files from the non-participants that the research team had access to did not include any data of co-morbidities, so it was not possible to compare participants to non-participants regarding co-morbidities.

\section{Conclusion}

The extent of ADL ability impairments in everyday life encountered by our sample of newly arrived asylum seekers was substantial. $27 \%$ had ADL motor ability measures and $35 \%$ ADL process ability measures below the AMPS competence cut off for effortless and efficient ADL task performance. Further, high ratings of low well-being, psychological distress and persistent pain were present. Given the complexity of the health and social consequences of torture, refugee trauma and a life in exile, it is 
essential that future research address how individual characteristics and the social environment influence ADL-impairment and development of disability. The right to rehabilitation is part of international legal standards as described in the United Nations Declaration of Human Rights. Therefore, early intervention and a coordinated rehabilitation effort rooted in a bio-psychosocial paradigm could be pathways to prevent chronification and further loss of ADL ability in traumatized asylum seekers and torture survivors already at arrival. Future studies should include larger samples with a relatively even distribution of tortured and non-tortured asylum seekers and eventually include quota refugees as well, as the difference in legal status might influence the ADL ability. Also, studies of potential differences in observed and self-reported ADL ability would provide valuable knowledge.

\section{Acknowledgments}

Deeply felt thanks to Bettina Toftgaard, Bettina Bratshaug, Svend-Erik Brande and the rest of the health personnel at the Red Cross Centers for supporting the data collection and to Eva Wæhrens, $\mathrm{PhD}$, at the Parker Institute for support in the use of AMPS. We also wish to thank the following for their financial support: The Metropolitan University College, Copenhagen, the Danish Occupational Therapy Association, Inge Genefke and Bent Sørensen Fund against Torture and the Oak Foundation.

\section{References:}

1. The Danish Immigration Service. Conditions for asylum seekers [Internet]. 2013 [updated 2013 June; cited 2013 Apr 29]. Available from: http://www.nyidanmark.dk/en-us/coming_to_dk/ asylum/conditions_for_asylum_applicants/conditions_for_asylum_applicants.htm

2. Danish Red Cross. Asylum [In Danish: Asyl] 2013 [cited 2013 Apr 29]. Available from: http:// www.rodekors.dk/det-goer-vi/asyl/asylarbejdet-idanmark/dagligdagen-som-asylansoeger

3. Sveaass, N. Gross human rights violations and reparation under international law: approaching rehabilitation as a form of reparation. European journal of psychotraumatology 2013, 4.

4. United Nations Commission Against Torture (CAT). General Comment No. 3. Geneva 2012. Available from: http://docstore.ohchr. org $/$ SelfServices $/$ FilesHandler. ashx? enc $=6 \mathrm{Qk}-$ G1d\%2fPPRiCAqhKb7yhskvE\%2bTuw1 mw\%2 fKU18dCyrYrZkEy\%2fFL18WFrnjCrilKQJsGK Tk4ahjqjet\%2bDd1I6EaK00bugJwE2JY\%2bYdP JjTZnS4TICxPO2OCjQAQvYuMtmAA

5. Fisher AG, Jones KB. Assessment of Motor and Process Skills. Volume 1: Development, Standardization, and Administration Manual. (7th ed.) Fort Collins, CO: Three Star Press; 2010.

6. World Health Organisation. International Classification of Function, Disability and Health. (resolution WHA 54.21). World Health Organisation. May 2011. Available from: http://www.who. int/classifications/icf/en/

7. Prip K, Persson AL, Sjølund BH. Self-reported activity in tortured refugees with long-term sequelae including pain and the impact of foot pain from falanga - a cross-sectional study. Disabil Rehabil. 2011;33(7):569-78.

8. Morville AL, Erlandsson LK. The Experience of Occupational Deprivation in an Asylum Centre: The Narratives of Three Men. J Occup Sci. 2013 June 14;20(3):212-223.

9. Kielhofner G, Borell L, Holzmueller R, Jonsson $\mathrm{H}$, Josepsson S, Keponen R, et al. Crafting Occupational Life. In: Kielhofner G, editor. Model Of Human Occupation. Baltimore, Maryland: Lippincott Williams \& Wilkins; 2008. p. 110-25.

10. Townsend E, Stanton S, Law M, Polatajko H, Baptiste S, Thompson-Franson T. et al. Enabling Occupation: An occupational Therapy Perspective. Ottawa: CAOT; 1999.

11. Månsson E, Lexell J. Performance of activities of daily living in multiple sclerosis. Disabil Rehabil. 2004 May 20;26(10):576-85.

12. Eklund M, Leufstadius C. Relationships between occupational factors and health and well-being in individuals with persistent mental illness living in the community. Can J Occup Ther. 2007 Oct $4 ; 74(4)$.

13. Masmas TN, Møller E, Buhmannr C, Bunch V, Jensen JH, Hansen TN, et al. Asylum seekers in 
Denmark-a study of health status and grade of traumatization of newly arrived asylum seekers. Torture. 2008; 18(2):77-86.

14. Nørredam M, Garcia-Lopez A, Keiding N, Krasnik A. Risk of mental disorders in refugees and native Danes: a register-based retrospective cohort study. Soc Psychiatry Psychiatr Epidemiol. 2009 Dec;44(12):1023-9.

15. Jaranson JM, Butcher J, Halcon L, Johnson DR, Robertson C, Savik K, et al. Somali and Oromo refugees: correlates of torture and trauma history. Am J Public Health. 2004 April;94(4):591-8. DOI: $10.1016 /$ j.jadohealth.2003.08.00.

16. Williams AC, Amris K. Pain from torture. Pain. 2007 Dec 15;133(1-3):5-8. (PubMed PMID: 18006232. Epub 2007/11/17. eng. DOI: 10.1016/j.pain.2007.10.001).

17. Danneskiold-Samsøe B, Barthels EM, Genefke I. Treatment of torture victims-a longitudinal clinical study. Torture. $2007 ; 17(1): 11-7$.

18. Thomsen AB, Eriksen J, Smidt-Nielsen K. Chronic pain in torture survivors. Forensic Sci Int. 2000 Feb 28;108(3):155-163.

19. Olsen DR, Montgomery E, Bøjholm S, Foldspang A. Prevalence of pain in the head, back and feet in refugees previously exposed to torture: A ten-year follow-up study. Disabil Rehabil. 2007 Jan 30;29(2):163-71.

20. Persson D, Erlandsson L, Eklund M, Iwarsson $\mathrm{S}$. Value Dimensions, meaning and Complexity in Human Occupation - A Tentative Structure for Analysis. Scand J Occup Ther. 2001; 8(1):718.

21. Amris K, Waehrens EE, Jespersen A, Bliddal H, Danneskiold-Samsoe B. Observation-based assessment of functional ability in patients with chronic widespread pain: a cross-sectional study. Pain. 2011 Nov; 152(11):2470-6. DOI.

22. WMA Declaration of Tokyo - Guidelines for Physicians Concerning Torture and other Cruel, Inhuman or Degrading Treatment or Punishment in Relation to Detention and Imprisonment. Tokyo, Japan: World Medical Assembly; October 1975 (updated May 2006). Available from: http:// www.wma.net/en/30publications/10policies/c18/ index.html.

23. Bech P. Measuring the dimensions of psychological general well-being by the WHO-5. QoL Newsletter. 2004; 32: 15-16.

24. Bech P, Rasmussen NA, Olsen LR, Nørholm V, Abildgaard W. The sensitivity and specificity of the Major Depression Inventory, using the Present State Examination as the index of diagnostic validity. J Affect Disord. 2001 Oct;66(2-3):15964.
25. Ware JE, Sherbourne CD. The MOS 36-item short form health survey (SF-36). I. Conceptual framework and item selection. Med Care 1992 Jun;30(6):473-83.

26. Bowling A. Just one question: If one question works, why ask several? J Epidemiol Community Health. 2005 May;59(5):342-5.

27. Freynhagen R, Baron R, Gockel U, Tölle TR. painDETECT: a new screening questionnaire to identify neuropathic components in patients with back pain. Curr Med Res Opin 2006 Oct;22(10):1911-20.

28. von Elm E, Altman DG, Egger M, Pocock SJ, Gøtzsche PC, Vandenbroucke JP, et al. The Strengthening the Reporting of Observational Studies in Epidemiology (STROBE) Statement: Guidelines for reporting observational studies. Ann Intern Med. 2007 Oct;147(8):573-7.

29. Gurr R, Quiroga J. Approaches to torture rehabilitation: a desk study covering effects, costeffectiveness, participation, and sustainability. Torture. 2001 March; 11(1a).

30. Steel Z, Chey T, Silove D, Marnane C, Bryant RA, van Ommeren M. Association of torture and other potentially traumatic events with mental health outcomes among populations exposed to mass conflict and displacement: a systematic review and meta-analysis. JAMA. 2009 Aug 5;302(5):537-49.

31. Edston E. The epidemiology of falanga--incidence among Swedish asylum seekers. Torture. 2009;19(1):27-32.

32. Crooks VA. Exploring the altered daily geographies and lifeworlds of women living with fibromyalgia syndrome: A mixed-method approach. Soc Sci Med. 2007 Feb;64(3):577-88. 33. Cohen J. Statistical power analysis for the behavioural sciences. New York: Academic Press; 1988.

34. Asmundson GJ, Coons MJ, Taylor S, Katz J. PTSD and the experience of pain: Research and clinical implications of shared vulnerability and mutual maintenance models. Can J Psychiatry. 2002 Dec;47(10):930-7.

35. Bryant RA, Marosszeky JE, Crooks J, Baguley IJ, Gurka JA. Interaction of posttraumatic stress disorder and chronic pain following traumatic brain injury. J Head Trauma Rehabil. 1999 Dec;14(6):588-94.

36. Moreno A, Grodin MA. Torture and its neurological sequelae. Spinal Cord. 2002 May;40(5):213-23.

37. Prip K, Persson AL. Clinical findings in men with chronic pain after falanga torture. Clin J Pain. 2008 Feb;24(2):135-41. 